\title{
Strategies for discovery of small molecule radiation protectors and radiation mitigators
}

\section{Joel S. Greenberger ${ }^{1}$ *, David Clump ${ }^{1}$, Valerian Kagan ${ }^{2}$, Hülya Bayir ${ }^{3}$, John S. Lazo ${ }^{4}$, Peter Wipf $^{5}$, Song Li $^{6}$, Xiang $\mathrm{Gao}^{6}$ and Michael W. Epperly ${ }^{1}$}

${ }^{1}$ Radiation Oncology Department, University of Pittsburgh Cancer Institute, Pittsburgh, PA, USA

${ }^{2}$ Environmental and Occupational Health Department, University of Pittsburgh, Pittsburgh, PA, USA

${ }^{3}$ Critical Care Medicine Department, University of Pittsburgh Medical Center, Pittsburgh, PA, USA

${ }^{4}$ Pharmacology Department, University of Virginia, Charlottesville, VA, USA

${ }^{5}$ Department of Chemistry, Accelerated Chemical Discovery Center, University of Pittsburgh, Pittsburgh, PA, USA

${ }^{6}$ Pharmaceutical Science Department, University of Pittsburgh, Pittsburgh, PA, USA

\section{Edited by:}

Sean Collins, Georgetown University Hospital, USA

\section{Reviewed by:}

Anatoly Dritschilo, Georgetown University School of Medicine, USA

Simeng Suy, Georgetown University Hospital, USA

\section{*Correspondence:}

Joel S. Greenberger, Department of

Radiation Oncology, University of

Pittsburgh Cancer Pavilion, Room

533, 5150 Centre Avenue, Pittsburgh, PA 15232, USA.

e-mail: greenbergerjs@upmc.edu
Mitochondrial targeted radiation damage protectors (delivered prior to irradiation) and mitigators (delivered after irradiation, but before the appearance of symptoms associated with radiation syndrome) have been a recent focus in drug discovery for (1) normal tissue radiation protection during fractionated radiotherapy, and (2) radiation terrorism counter measures. Several categories of such molecules have been discovered: nitroxide-linked hybrid molecules, including GS-nitroxide, GS-nitric oxide synthase inhibitors, p53/mdm2/mdm4 inhibitors, and pharmaceutical agents including inhibitors of the phosphoinositide-3-kinase pathway and the anti-seizure medicine, carbamazepine. Evaluation of potential new radiation dose modifying molecules to protect normal tissue includes: clonogenic radiation survival curves, assays for apoptosis and DNA repair, and irradiation-induced depletion of antioxidant stores. Studies of organ specific radioprotection and in total body irradiationinduced hematopoietic syndrome in the mouse model for protection/mitigation facilitate rational means by which to move candidate small molecule drugs along the drug discovery pipeline into clinical development.

Keywords: radiation mitigators, radioprotectors, small molecules, mitochondria

\section{INTRODUCTION}

Drug discovery in the areas of radiation protectors and mitigators focus on the goal of developing small molecules that are easily administered, rapidly deliverable, and well tolerated by recipients in two primary scenarios: (1) clinical radiation therapy (where fractionated irradiation is delivered to specific target volumes), and (2) systemic administration as part of the Radiation Counter Measures Program of the National Institute of Allergies and Infectious Disease at the National Institute of Health (Stone et al., 2004). One approach toward drug discovery in the area of radiation protectors and mitigators is to follow-up on previous studies in radioprotective gene therapy for clinical radiotherapy (Greenberger et al., 2003; Tarhini et al., 2011).

Manganese superoxide dismutase-plasmid liposomes (MnSODPL) were developed as a clinical therapeutic for administration to the esophagus by swallowed plasmid liposomes (Stickle et al., 1999; Epperly et al., 2000a, 2001a, 2004c, 2005a,b; Niu et al., 2008; Rajagopalan et al., 2010). This method delivers a plasmid containing the transgene (Epperly et al., 2001a) and was motivated by extensive animal studies in the mouse model in which radiation esophagitis from single fraction (Stickle et al., 1999) or fractionated irradiation (Epperly et al., 2001c) of the thoracic cavity (head and neck and abdomen shielded) showed that irradiation damage could be significantly ameliorated by esophageal administration of MnSOD-PL.
The concept of using MnSOD transgene expression for radiation protection followed upon studies in which MnSOD was demonstrated to be one of the rapid upregulated cellular response products to ionizing irradiation in tissues (Epperly et al., 1998, 1999a,b; Greenberger, 2008, 2009; Belikova et al., 2009b). The concept of developing MnSOD-PL was based on radiobiology studies demonstrating that the MnSOD transgene product was uniquely mitochondrially localized (SOD2) compared to the cytoplasmic superoxide dismutase (SOD1) or extracellular SOD3 (Epperly et al., 2003e). When the specific mitochondrial targeting sequence on SOD2 was inserted on to SOD1, the transgene product localized to the mitochondria and produced a CU/ZnSOD metalloenzyme that was also radioprotective for $32 \mathrm{D} \mathrm{cl} 3$ cells in vitro (Epperly et al., 2002b, 2003e). In contrast, deleting the mitochondrial targeting sequence of SOD2 resulted in a cytoplasmic manganese metalloenzyme with little radioprotective capacity (Epperly et al., 2003e). MnSOD transgene delivery to animals was optimized using plasmid liposomes (Epperly et al., 2005b; Zhang et al., 2008b), adenovirus (Zwacka et al., 1998), and other transgene delivery systems (Greenberger et al., 2003). Plasmid liposomes were considered to be the safest delivery system (Greenberger et al., 2003). Elimination of potential immunologic responses to viral sequences using virus vectors and careful optimization of liposome delivery vehicles with cationic properties lead to design of a MnSOD-PL construct suitable for delivery in animal 
model systems by either intra-oral/oropharyngeal administration (Epperly et al., 1999a; Guo et al., 2003a,b,c), intra-esophageal delivery (Stickle et al., 1999), or delivery into the lungs by either intra-tracheal injection or inhalation using a nebulizer system (Epperly et al., 1998; Carpenter et al., 2005; Bernard et al., in press). In all of these systems, a significant radiation protection of specific organs was documented by the physiological, pathophysiological, and histopathological evidence of decreasing both acute and chronic radiation side effects (Epperly et al., 1999b). Of particular interest, was the demonstration that prevention of early radiation esophagitis using MnSOD-PL swallow also decreased the severity and incidence of late esophageal stricture (Epperly et al., 2001a). That MnSOD-PL was working by quenching superoxide was documented in an in vitro assay system using ascorbate to measure antioxidant capacity and in other studies by documenting that MnSOD overexpression resulted in decreased depletion of antioxidant stores within cells and tissues, principally glutathione (Epperly et al., 2004a). Small molecule drugs designed next followed at first the principle of duplicating or mimicking the action of MnSOD transgene product.

This review describes efforts in several areas of post-MnSODPL drug discovery. A pathway from cell culture experiments, to animal models, to efficiency in human cells, and then to the point of establishing parameters for drug development, is being pursued (Table 1).

\section{MATERIALS AND METHODS}

The methods for production and synthesis of GS-nitroxides, GS-nitric oxide synthase inhibitors (NOS-I), p53/mdm2/mdm4 inhibitors, have been published previously (Rwigema et al., 2011).

The construction of p53-upregulated modulators of apoptosis (PUMA) inhibitors has been described in previous publications (Qiu et al., 2008; Mustata et al., 2011).

Methods for constructing MnSOD-PL, and delivery systems have been described (Tarhini et al., 2011).

Drug formulation/delivery systems for constructing three emulsions for organ specific delivery of small molecules have been described previously (Epperly et al., 2010d; Kim et al., 2011b).

\section{DRUG DISCOVERY BY SIRNA LIBRARY SCREENING}

The high-throughput methodologies for utilizing human cells in culture transfected with siRNA library targeting the druggable genome have been described previously and the paradigm for screening radiation protectors (siRNA delivered before

Table 1 | Drug discovery pathways for small molecule radiation protector/mitigator agents.

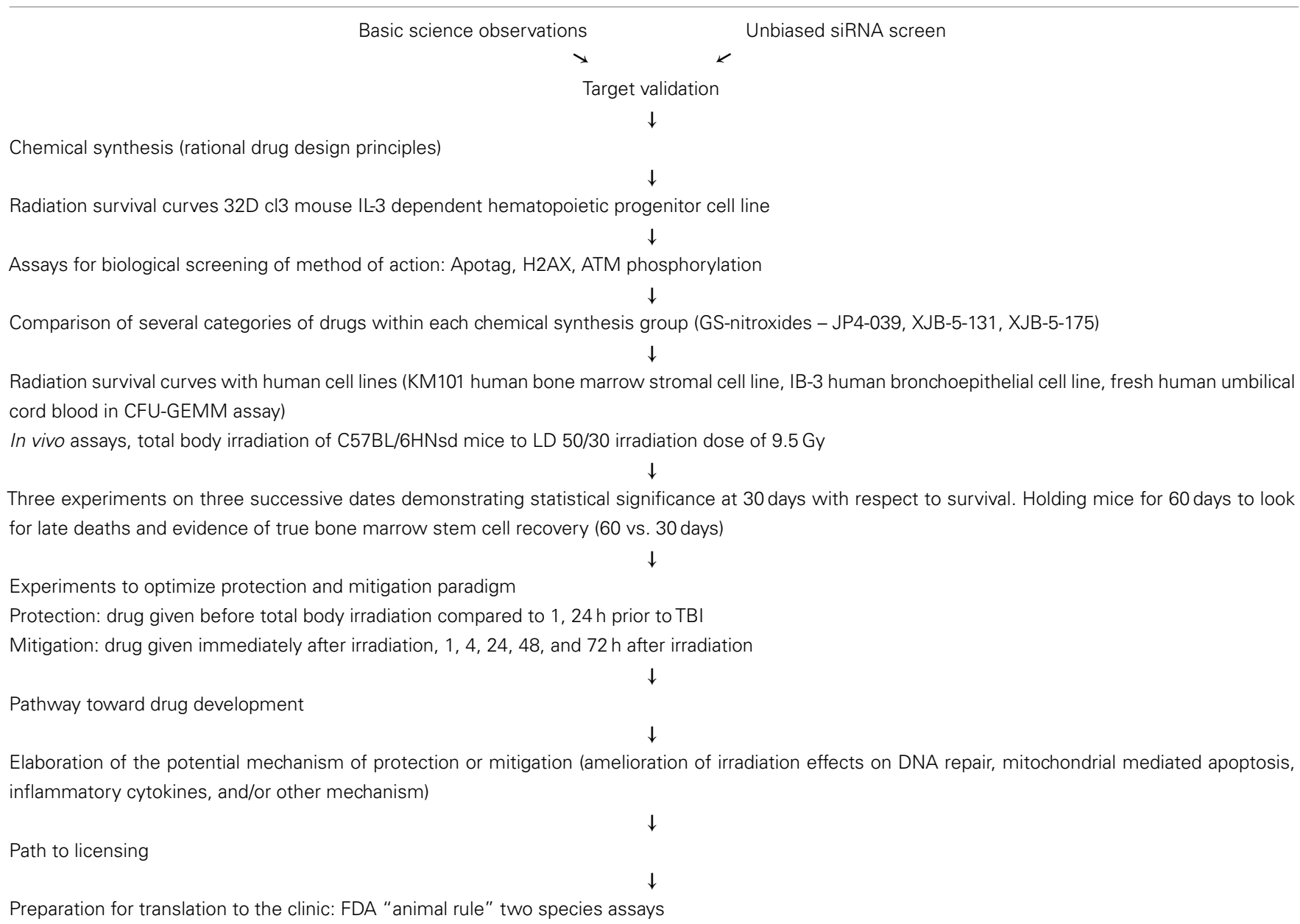


irradiation) and radiation mitigators (siRNA delivered after irradiation of cells in culture; Jiang et al., 2009a; Zellefrow et al., in press) have been described.

Methods for construction and design of phenylphosphonium conjugated imidazole-fatty acids and TTP conjugated nitroxides have been described previously (Stoyanovsky et al., 2009; Atkinson et al., in press).

The synthesis and description of metalloporphyrin based superoxide dismutase mimics have been described previously (Stoyanovsky et al., 2011).

\section{ANIMALS AND IRRADIATION}

C57BL/6/HNsd female mice 30-33 g were irradiated to organ specific sites including head and neck, thoracic cavity according to published methods (Epperly et al., 1998, 1999b; Stickle et al., 1999). These animal studies were carried out using a linear accelerator with blocking specific sites in anesthetized mice irradiated to several protocols to treat the head and neck region, the thoracic cavity (Epperly et al., 1998; Stickle et al., 1999) with head and neck (Epperly et al., 2007a) and abdomen shielded, or specific bones in the setting of studies for unicortical bone wound healing (Gokhale et al., 2010) experiments.

Total body irradiation (TBI) was delivered by a Gamma Cell Cesium Irradiator dose rate $70 \mathrm{cGy} / \mathrm{min}$ using a Lucite tray immobilization device with non-anesthetized mice, according to published methods (Rwigema et al., 2011).

\section{CLINICAL RETROSPECTIVE STUDY OF POSSIBLE CLINICALLY AVAILABLE RADIOPROTECTORS BASED ON RADIOBIOLOGY EXPERIMENTS}

The University of Pittsburgh Institutional Review Board reviewed and approved a pilot project that analyzed the complications of patients taking glyburide (Jiang et al., 2009a) and/or carbamazepine (Kim et al., 2011a) while receiving definitive radiotherapy (IRB no. PR011030146). Between January, 2006 and January, 2011, patients receiving definitive radiotherapy which was defined as those receiving greater than 25 fractions for non-small cell lung carcinoma or head and neck squamous cell carcinoma were identified. The IRB approved a waiver of informed consent/HIPAA authorization to access, record, and use protected patient health information/patient medical record information. A subsequent mining of the electronic medical record identified 20 patients that were concurrently prescribed either carbamazepine and/or glyburide. The radiation oncology treatment record and follow-up information were reviewed to determine treatment parameters and presence or absence of early and/or late toxicities. Local control was assessed by reviewing the follow-up history and physicals, while also accessing available imaging and reports. Date of death was determined by either reports in the electronic medical record or by information available in the social security death index.

\section{RESULTS}

\section{GS-NITROXIDES}

The first series of drugs developed for preferred delivery of nitroxides to mitochondria were the Hemigramicidin Nitroxides (Wipf et al., 2005; Fink et al., 2007a,b; Jiang et al., 2007; Jiang et al., 2008; Rajagopalan et al., 2009). Nitroxides have previously been found to be effective small molecule free radical scavengers (Kagan et al., 2009a). Ionizing irradiation induces highly reactive free radicals, including superoxide, nitric oxide, and hydroxyl radical. Superoxide in combination with nitric oxide forms peroxynitrite, a potent oxidant with a propensity to oxidize lipids. Superoxide radical anion and peroxynitrite produce significant oxidative stress at the mitochondrial membrane, leading to membrane permeability, cytochrome $\mathrm{C}$ leakage, and induction of apoptosis. The problem with small molecule nitroxides such as 4-amino-tempo or tempol, is the requirement for high concentrations of drug to deliver the desired radioprotective or radiation mitigative effects (Zhang et al., 2008a). Systemic administration is often associated with hypotension and renal pathology in the mouse model (Zhang et al., 2008a). To improve the efficiency and feasibility of the use of nitroxides, a method for mitochondrial targeting of these agents was developed. Two orthogonal strategies for mitochondrial targeting included: (1) attaching a peptide isostere sequence of the antibiotic, GS, to the nitroxide, resulting in the GS-nitroxides (Wipf et al., 2005; Fink et al., 2007a,b; Jiang et al., 2008), and (2) attaching triphenylphosphonium cations, a charge-driven mitochondrial targeting moiety (Jiang et al., 2009b; Stoyanovsky et al., 2009). Both chemical synthesis strategies resulted in a highly efficient targeting of nitroxides to the mitochondrial membrane, yielding a 33- to 600 -fold concentration of drug in mitochondria as determined by electron spin trap analysis (Kagan et al., 2009c) or visualization of a fluorochrome-tagged GS-nitroxide (Bernard et al., 2011a). In support of the crucial role of mitochondrial targeting, significant radiation protection was achieved using GS-nitroxide at low micromolar concentrations in cell culture compared to nitroxide alone. Furthermore, concentrations of GS-nitroxide of $5 \mathrm{mg} / \mathrm{kg}$ delivered to mice i.v. or i.p. resulted in considerable total body radioprotection and organ specific radioprotection of the esophagus during single fraction or fractionated irradiation (Epperly et al., 2010d; Kim et al., 2011b). Recent data confirm and extend published results and show mitigation out to $72 \mathrm{~h}$ after TBI at the LD $_{50 / 30}$ dose (Figure 1).

\section{GS-NITRIC OXIDE SYNTHASE INHIBITORS}

A source of reactive nitrogen species (RNS), such as peroxynitrite formation, nitric oxide, was targeted in radiation protection and mitigation strategies by the preparation of mitochondrial targeted GS-NOS-I. Several of these synthetic derivatives were shown to target mitochondria with equal efficiency as GS-nitroxides

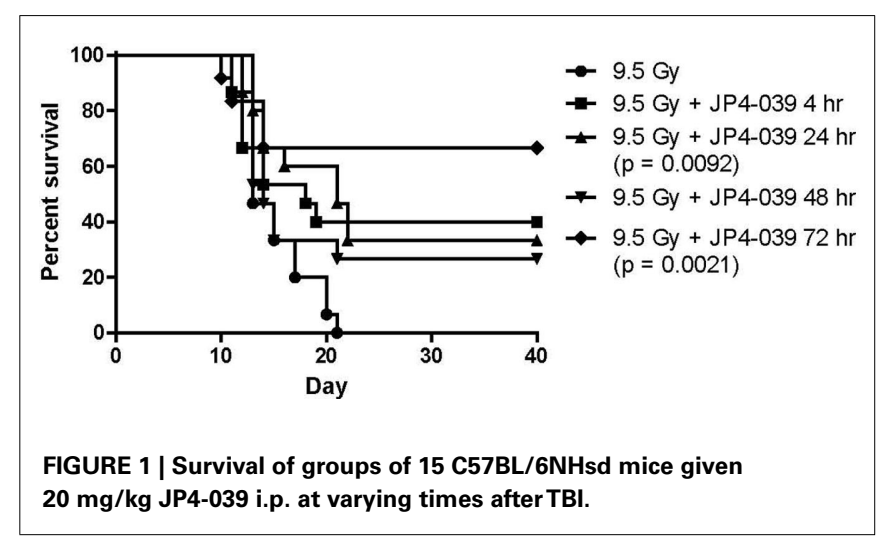


(Rwigema et al., 2011; Bernard et al., 2011b). While potent in vitro with respect to the modulation of irradiation killing in clonogenic survival curves, GS-NOS-I drugs were not as effective as GS-nitroxides in vivo for total body radioprotection, based on the amount of drug required for significant protection at 30 days in the $\mathrm{LD}_{50 / 30}$ dose of TBI or by the more strict criteria of efficiency at delivery $72 \mathrm{~h}$ after irradiation in the Radiation Counter Measures Program. A combination of both GS-nitroxide and GS-NOS-I in a single administration was not more effective than one drug alone (Rwigema et al., 2011). Because of the superior dose response cures and effectiveness of administering GS-nitroxides as late as $48 \mathrm{~h}$ after TBI (Figure 1), we focused on the development of more potent GS-nitroxide molecules as well as their formulation in further rounds of drug discovery.

\section{p53/mdm2/mdm4 INHIBITORS}

A third category of mitochondrial targeted small molecules with radioprotective and radiomitigative properties was represented by $\mathrm{p} 53 / \mathrm{mdm} 2 / \mathrm{mdm} 4$ inhibitors. Rapidly after ionizing radiation of cells, tissues, or organs, p53 is upregulated (Rwigema et al., 2011). This critical molecule is involved in both modulation of cell cycle progression and upregulation of cell cycle checkpoints, and it is at the crossroads of determination of either cell recovery or induction of apoptosis (Rwigema et al., 2011). In response to $\mathrm{p} 53$, there is upregulation of $\mathrm{mdm} 2$ and $\mathrm{mdm} 4$, which counteract and can neutralize p53 (Rwigema et al., 2011). Accordingly, small molecule drugs developed to prevent $\mathrm{mdm} 2$ and $\mathrm{mdm} 4$ from binding to p53, leaving p53 available (theoretically), and to regulate a greater degree of cell repair and influence less apoptosis in the setting of modest DNA damage (Rwigema et al., 2011). Several categories of $\mathrm{p} 53 / \mathrm{mdm} 2 / \mathrm{mdm} 4$ were tested and found to be protective and mitigative of irradiated cells in culture (Rwigema et al., 2011). However, as with the GS-NOS-I, drug dose response curves required higher doses of drug for effectiveness, and drugs in this category, notably BEB-55, were only effective when delivered very rapidly after irradiation (Kim et al., 2011b; Rwigema et al., 2011). The ineffectiveness at $24 \mathrm{~h}$ after irradiation made this drug delivery system less attractive. Combining BEB-55 with either GSNOS-I, GS-nitroxides, or in combinations with both drugs (three drug cocktail) was not more effective than one drug alone. These studies demonstrated several principles of small molecule drug discovery, namely the potential lack of additive or synergistic interaction between drugs which, while having different biochemical properties, target the radiation damage response at the same site (mitochondrial membrane). Also, they define the principle that similar targets of action may not produce similar outcomes with respect to dose response curves, timing of delivery, and efficiency of response.

\section{PUMA INHIBITORS}

Another strategy for developing radiation mitigators and protectors was based on a second known pathway of p53 interaction with small molecules to the mitochondrial membrane (Mustata et al., 2011). PUMA drugs were discovered in studies looking at downstream events following p53 upregulation during irradiation. PUMA homozygous recombinant deletion mice, $\mathrm{PUMA}^{-1-}$ mice were shown to be radioresistant, particularly to abdominal irradiation, which caused less death of intestinal crypt cells (Qiu et al., 2008). Small molecule PUMA inhibitors were developed to counteract PUMA interaction with p53 in a strategy similar to that for $\mathrm{p} 53 / \mathrm{mdm} 2 / \mathrm{mdm} 4$ inhibitors, but with knowledge that activated p53 might be more stable in the setting of PUMA inhibitors. These experiments showed significant radiation protection and mitigation in vitro and in vivo. Chemical library screening for drugs with capacity to block PUMA binding to p53 but also to dislodge the binding once achieved, made this class of molecules quite attractive for further drug discovery (Mustata et al., 2011).

\section{SIRNA LIBRARY SCREENING FOR RADIATION MITIGATORS}

Following on a siRNA library assay, that discovered glyburide as a radiation protector (Jiang et al., 2009a), we developed a strategy to discover radiation mitigators. The NCCIT human pluripotent embryonic carcinoma cell line was chosen for these experiments (Zellefrow et al., in press), because of its suitability for the 384 well plate format used with the siRNA library screening and also because of its radiobiology being similar to that for human hematopoietic stem cell known to be critical targets for the human hematopoietic syndrome that follows TBI (Zellefrow et al., in press). siRNA library screening revealed several small molecules that regulate mitochondrial functionality including PI-3 kinase inhibitors (Zellefrow et al., in press).

\section{TTP CONJUGATED IMIDAZOLE-FATTY ACIDS}

The mechanism of irradiation-induced apoptosis has been a focus of intense investigation by many laboratories (Bayir et al., 2006; Kagan et al., 2006; Tyurin et al., 2008; Tyurina et al., 2008; Kagan et al., 2009a; Tyurin et al., 2009, 2010, 2011). One recent finding has been the importance of cardiolipin binding to cytochrome $\mathrm{C}$, to keep the latter molecule within the mitochondrial membrane, and prevent its separation and leakage into the cytoplasm where it activates the caspase system and initiates apoptosis (Kagan et al., 2009b). Separation of cardiolipin from cytochrome C was shown to be influenced by the phospholipid synthesis required for mitochondrial lipid construction. Two mitochondrial lipids shown to be specifically oxidized following irradiation were cardiolipin and phosphatidylserine. Cardiolipin, because of its importance in immobilizing and stabilizing cytochrome C, was found to convert into a peroxidase rapidly after irradiation if mitochondrial generated free radicals were not neutralized (Belikova et al., 2007; Atkinson et al., in press). Separation of cardiolipin from cytochrome $\mathrm{C}$ was felt to be a critical event, which, when inhibited, might result in stabilization of the mitochondria and decrease events leading to apoptosis. Accordingly, this class of molecules turned imidazole-fatty acids into constructive targets of the mitochondrial membrane using the triphenylphosphonium cation, charge-mediated mitochondrial targeting mechanism referenced above for nitroxides. TTP-Imidazole-Fatty Acids were demonstrated to rapidly accumulate in the mitochondria and by blocking critical steps in the biochemistry of cardiolipin separation from cytochrome $\mathrm{C}$, acted as potent radiation protectors and mitigators (Atkinson et al., in press). 


\section{METALLOPORPHYRIN SUPEROXIDE DISMUTASE MIMICS}

Previous studies by many laboratories have stressed the importance of duplicating the original MnSOD-PL gene therapy radiation protection and mitigation experiments by constructing small molecule SOD mimics and targeting these to the mitochondria (58). The first SOD mimics were highly effective against cells in culture and in the C. elegans experiments shown to have significant antioxidant properties. As with the original experiments with Tempol, gaining sufficient concentration of SOD mimics in the mitochondria were shown to be a potentially limiting step (Kagan et al., 2009c; Stoyanovsky et al., 2009, 2011). Toxicity of many of the effective molecules in vitro was observed when the drugs were given in vivo. Based on the studies with mitochondrial targeting of other small molecules, TTP was attached to metalloporphyrin molecules and initial constructed drugs were shown to be highly effective and as with other mitochondrial targeted small molecules much more effective in dose response administration, timing experiments, and in multiple administration paradigms.

\section{THE IMPORTANCE OF FORMULATION CHEMISTRY FOR A SUITABLE DRUG DELIVERY SYSTEM}

Rational drug development involves animal testing to ensure safety and efficacy in humans. In many cases, in vitro radiation survival curves and biochemistry assays utilize solvent for newly discovered drugs, which are easily adapted to tissue culture. For example, dimethylsulfoxide (DMSO) is a valuable solvent for testing many categories of drugs, as is ethanol. The radiation studies can often be carried out using tissue culture cell lines for clonogenic survival curves or apoptosis assays and the solvents themselves generally produce no effect on the radiobiology or the parameters being studied. However, once a drug is delivered to an animal, the investigator often finds that the solvent being used is itself a radiation protector or mitigator (as in the case of DMSO) or it can be toxic to the experimental animal of choice (as is the case in ethanol treatment of mice; Rwigema et al., 2011).

For this reason, formulation chemistry has been critical to the process of drug discovery in the areas of radiation protection and mitigation. We have developed novel formulations/emulsions for topical delivery of radiation protective agents to the skin and also for systemic administration. The F14 emulsion, which is described in detail in a recent publication (Goff et al., 2011) was developed in the University of Pittsburgh School of Pharmacy with specific attention to preserving the functionality of drug (GS-nitroxide or GS-NOS-I) capacity for entry of cells, and transcellular migration to the mitochondrial membrane, with the importance of preserving systemic distribution. The F14 emulsion combines the properties of liposomal, lamellar combining of drugs between layers of lipid, and the critical particle size, which allows uptake in cells within the smallest capillaries and transcapillary spaces vs. systemic distribution. In contrast, a F15 emulsion was developed for delivery of the same drug, but with attention to the concept of local concentration of the drug in the esophagus. This F15 emulsion, which includes the detergent agent, Tween, is similarly constructed of lamellar liposomes, and facilitates the maintenance of the drug locally in the esophagus for prolonged and more efficient uptake and decreased penetration through the tissue into the circulation (Epperly et al., 2010d; Kim et al., 2011b).
Many studies in the drug development of small molecule radioprotectors and mitigators failed during the translation of the research from tissue culture to animal model systems. This often can be the result of unanticipated toxicities, rapid metabolism, extensive plasma protein binding, poor pharmacokinetics, or invalid molecular targeting leading to a lack of intrinsic efficacy. The importance of formulation chemistry is a process that should not be underestimated in the frequent failures.

\section{PRELIMINARY RESULTS OF A CLINICAL RETROSPECTIVE STUDY}

We sought to determine whether two newly identified radiation protectors in the clinical pharmacopeia were radiation protectors for normal tissue in patients. Such a discovery would be a valuable and cost effective result. A retrospective analysis of patients treated with definitive radiotherapy for non-small cell lung carcinoma or head and neck squamous cell carcinoma between January, 2006 and January, 2011 was carried out and identified 20 patients that were prescribed either carbamazepine (Kim et al., 2011a) and/or glyburide (Jiang et al., 2009a). We searched for competing comorbidities during their course of radiation therapy. Treatment parameters including the prescribed dose, fractionation schedule, and elapsed days of treatment as well as the acute and late toxicity profile for each patient were examined. A relationship between patients receiving either carbamazepine and/or glyburide and a reduction in morbidity was measured as the grade of toxicity and whether it mirrored that expected for these treatment populations. These medications were also evaluated for any reduction in suspected local control probability. These preliminary results were designed to question whether further investigation into the use of either of these medications as radiation protectors or mitigators would be worthwhile.

\section{DISCUSSION}

There is a compelling need for new radiation protectors and radiation damage mitigators that improve clinical outcomes in two scenarios: clinical radiotherapy and radiation countermeasures. Clinical radiotherapy is dependent upon the therapeutic ratio: tumor cell kill relative to normal tissue damage. Improvements in radiation beam collimation through the use of multi-leaf collimators, Intensity Modulated Radiotherapy, and, most recently, Stereotactic Radiosurgery Imaged Guided Radiotherapy, greatly improve the ability of radiation oncologists and physicists to target tumor volumes and minimize dose to the transit volume of normal tissue (Epperly et al., 1998; Stickle et al., 1999). However, as radiation dose escalation protocols increase dose, and as more toxic chemotherapy drugs are using combined modality protocols, the issue of normal tissue damage during clinical radiotherapy is critical. Available radiation protectors for normal tissue have necessitated systemic delivery in most cases. The free radical scavenger WR2721 (amifostine; Movsas et al., 2005), which has provided some therapeutic benefit in protecting the salivary glands in head and neck cancer patients, but has been disappointing in other applications. For normal tissue protectors and damage mitigators, this principle is also important in brachytherapy, particularly interstitial therapy. The radiation source is implanted or transiently placed within tumor volumes to provide a high dose delivery to the target volume; however, surrounding tissues 
are also at risk for both acute and late radiation side effects (Epperly et al., 1998; Stickle et al., 1999). This is particularly prominent in brachytherapy seed implant for prostate cancer, and for endometrial and cervix cancer, as well as for recurrent pelvic tumors.

One approach toward altering the therapeutic ratio has been to sensitize tumors to irradiation (Hall and Giaccia, 2006). This approach has been exciting and potentially valuable; however, uniformity of distribution of radiosensitizing agents within the tumor has been problematic. Delivery systems that restrict radiosensitizer to tumor have led to complications in which normal surrounding tissues also become sensitized. The same problems become apparent in radiation protection and radiation mitigation. Normal tissue delivery often results in insufficient distribution of the agent to the tumor and the therapeutic effect is lost. Uniform distribution of a radioprotector/mitigator within normal tissues can also be problematic, and if greater than $50 \%$ of cells within a tissue must be affected directly by the radioprotector drug, there will be incomplete treatment. MnSOD-PL gene therapy for radiation protection went through a successful Phase I clinical trial for protection of the esophagus during 7.5 weeks of chemoradiotherapy of non-small cell lung cancer, and this therapy has now progressed to a Phase II trial (Tarhini et al., 2011). However, gene therapy remains controversial both for its concept as well as its general acceptance. The expense of producing any plasmid is a continuing concern as is the potential for long-term transgene expression and there are further concerns about transmission of transgene to other tissues or the germ line. These issues limit the role of gene therapy as a potentially valuable technology. However, the lessons learned from MnSODPL gene therapy have been important for small molecule drug design.

The principles developed in MnSOD-PL normal tissue radioprotection for clinical radiotherapy have helped guide targeted approaches for the protection and mitigation of normal tissue (Epperly et al., 1999c, 2000b,c, 2001b, 2002a,c, 2003a,b,c,d, 2004b,d,e, 2006a,b, 2007b,c,d, 2009, 2010a,b,e; Kanai et al., 2002; Niu et al., 2010). Measuring levels of normal tissue antioxidants and radiation protective physiologic responses has been a valuable concept. Utilizing MnSOD-PL transgene to lower the irradiation-induced production of TGF $\beta$, IL-1, TNF $\alpha$, and other inflammatory cytokines, has been helpful in reducing radiation side effects in animal models (Epperly et al., 1999b; Lechpammer et al., 2005; Greenberger and Epperly, 2009; Rajagopalan et al., 2010). The indirect effects of irradiation, coupled with the direct effects (consumption of antioxidant stores, mitochondrial membrane disruption, and activation of apoptosis) provide an attractive strategy for targeted normal tissue radioprotection. Furthermore, in a setting of fractionated radiotherapy, multiple local, tissue specific administrations of a radioprotective gene therapy approach also show that the drug is functioning in mitigation. Protection from the next fraction of irradiation is combined with mitigation of the effects of the previous fraction. While MnSOD-PL normal tissue radioprotective gene therapy continues as a realistic modality for therapeutic development, advances in development of small molecule radiation mitigators for the NIAID/NIH Radiation Countermeasures Program, have led to attractive new drug leads for clinical application in fractionated radiotherapy.

Small molecule radiation protectors and mitigators were developed for the radiation terrorism countermeasures program. Several basic principles were required for a successful application of delivery of a small molecule for use as a radiation countermeasure.

Most importantly, the drug must be a mitigator, delivered after radiation exposure. Realistically, this agent must be effective $24 \mathrm{~h}$ or later after irradiation (Rwigema et al., 2011). Such a delay from the time of irradiation exposure to the administration of the countermeasure is realistic in the scenario of a dirty bomb, radiological isotope dispersal, or direct irradiation exposure from a fission bomb. In fact, the NIAID/NIH has urged investigators in this area to provide information on administration of a radiation countermeasure 48 or $72 \mathrm{~h}$ after radiation exposure. Because radiation engages an array of signaling responses effecting cell survival and death, it is perhaps not surprising that many radiation protective agents fail when tested as radiation mitigators (Koide et al., 2011; Rwigema et al., 2011).

The discovery of radiation mitigators for the Center for Medical Counter Measures Against Radiation (CMCR) Program has followed several pathways based on the understanding of cellular and tissue responses to radiation from a molecular, biologic, and cell physiologic perspectives. These discoveries led to identification of several pathways of irradiation response, which could logically be modulated by small molecules, antibodies, cytokine receptor antagonists, or induction of other cell and tissue responses. Many new agents have been tested and shown to be promising (Table 2). A key variable in all of these experiments has been the requirement for delivery of the radiation mitigator $24 \mathrm{~h}$ or later after irradiation.

The time course of cellular, tissue, organ, and total body response to irradiation has been partially elucidated. In individual cells, initial DNA double strand breaks trigger a repair mechanism involving ATM kinase phosphorylation, proteins in the Fancone response pathway, and numerous other DNA repair processes (Bernard et al., 2011a). Initiation of this process, which is often complete within $45 \mathrm{~min}$ after irradiation exposure (Bernard et al., 2011a), leads to communication from the nucleus to the cytosol of numerous messengers in p53, stress activated protein kinases, and pro-apoptotic proteins, which act at the mitochondrial membrane. There is an increasing appreciation of the role of mitochondrial mechanisms of cellular apoptosis in the ionizing irradiation response (Pearce et al., 2001; Belikova et al., 2009a). This p53 pathway is in response to ionizing irradiation, other mechanisms

Table 2 | Categories of radioprotective and radiation mitigating agents currently under study.

\section{RADIATION PROTECTION}

MnSOD-PL

(GS-nitroxide) JP4-039

\section{RADIATION MITIGATION}

GS-nitroxide (JP4-039), XJB-5-131

TTP-imidazole-fatty acids

$\mathrm{Pl}-3$ kinase inhibitors

TTP-targeted metalloporphyrins (SOD mimic) 
of cell damage, including ischemia reperfusion, hypoxia, hyperoxia, traumatic injury, burn, and cytotoxic chemical exposure has identified critical pathways in potentially increasing cellular survival. The effects of p53 in regulating cell cycle check point, cell cycle arrests, anti- or pro-apoptotic signaling, and detecting cellular quiescence are a prominent focus. However, redundant systems in cells including p53-independent mechanisms of apoptosis and compensatory regulatory systems have led investigators in other directions. One common mechanism of irradiation-induced cell death involves oxidative stress (Greenberger et al., 2001; Epperly et al., 2004a; Zhou et al., 2008). Depletion of intracellular antioxidant stores, principally glutathione, decrease the capacity of cells to resist ionizing irradiation damage. These facts are demonstrated in the apoptosis assay of the first cell division and in clonogenic survival curve assays requiring several cell divisions for a colony scored as surviving (Greenberger et al., 2001; Epperly et al., 2004a). Many research programs have focused on these elements in developing small molecule antioxidants.

A major triumph in this area was the investigation of the nitroxide, Tempol, as a radiation protector/mitigator. Pioneering studies by Mitchell and colleagues (Zhang et al., 2008a) laid the ground for the clinical application of Tempol in reducing radiation dermatitis. A major problem with Tempol is the requirement for high systemic concentrations to provide acceptable levels at appropriate intracellular targets to produce radiation damage protection or mitigation. Furthermore, systemic doses of mitochondrial targeted MnSOD-PL were radioprotective, and radiation mitigative while comparable molar concentrations of Tempol were not (Zhang et al., 2008a,b). Understanding the role of MnSOD as a mitochondrial targeted antioxidant helped to rationalize the benefits of the mitochondrial targeting of nitroxides. Two strategies employed were the use of a GS-nitroxide hybrid molecule derived from the antibiotic gramicidin S (GS), and the attachment of triphenylphosphonium cation to the nitroxide to take advantage of a charge-driven delivery to mitochondria. These approaches provided agents with enrichment factors of 33- to 600-fold in the mitochondrial membrane over the cytosol as well as significant relative radioprotection (Wipf et al., 2005; Fink et al., 2007b; Jiang et al., 2008). The successful use of GS-nitroxide suggest a further investigation into other mitochondrial targeted molecules.

Other studies led to development of p53 stabilizing homologous $\mathrm{mdm} 2 / \mathrm{mdm} 4$ inhibitors, PUMA inhibitors, inhibitors of mitochondrial nitric oxide synthase and multiple approaches toward mitochondrial targeted superoxide dismutase mimics (Kanai et al., 2004; Stoyanovsky et al., 2009, 2011). Identification of multiple targets of small molecule antioxidant effects at the mitochondrial membrane, led to basic molecular studies of the critical interaction between cardiolipin and cytochrome $\mathrm{c}$ in the mitochondrial membrane. Oxidative stress in the mitochondria produces cytochrome c leakage. Small molecules that could stabilize the attachment of cytochrome $\mathrm{c}$ to cardiolipin might be effective radiation mitigators (Tyurin et al., 2008; Tyurina et al., 2008; Kagan et al., 2009a). These studies led to the identification of a TTP-mitochondrial targeted imidazole-fatty acid to prevent conversion of cytochrome $\mathrm{c}$ into a peroxidase and its secondary damage by oxidative damage to cardiolipin (Stoyanovsky et al., 2009, 2011). Clearly, many more small molecule radioprotectors and radiation mitigators will be developed in future years based on the concept of mitochondrial targeted antioxidative targets and the identification of the secondary effects of oxidative stress within the mitochondria. It remains to be seen whether distal steps following cytochrome c leakage from the mitochondria can also be interrupted with radiation mitigation. One report has suggested that cytochrome $\mathrm{c}$ leakage from the mitochondria is the "point of no return" and cell death then is inevitable, because the caspase pathway cannot be reversed at such a late step (Tyurin et al., 2008; Kagan et al., 2009a). This hypothesis also awaits further investigations. Initially, cells undergo apoptosis following irradiation, a cascade of secondary tertiary and further steps of cell destruction follows the oxidative stress microenvironment in dying tissues, and also through elaboration of inflammatory cytokines, which induce oxidative stress at distant sites (Greenberger and Epperly, 2007; Epperly et al., 2008, 2011). Each of these tissue and organ pathophysiologic actions of irradiation suggest that an appropriate radiation mitigation cocktail of drugs might include anti-inflammatory agents potentially so that it can counteract the cytotoxic effects of inflammatory cytokines.

For both clinical use in fractionated radiotherapy and for use as a radiation mitigator against radiation terrorism, small molecule drugs must be both effective and safe. Once drug discovery has met the criteria of effective radiation protection and/or mitigation, the issues of safety become paramount. A radiation countermeasure systemically applied to hundreds or thousands of potential radiation casualties must be easily administered. For this reason, drug development strategies have included plans for topical administration through a skin patch, done to avoid the cumbersome and often impractical cutaneous, intra-muscular, or intravenous routes. Furthermore, since nausea and vomiting after radiation exposure may preclude oral administration, the topical approach seems the most practical as well as feasible. It is desirable that a radiation mitigator be safe for administration to pregnant females and non-toxic and non-teratogenic for the developing fetus. Obviously, we would like the agents to be safe in children and in the elderly and not show significant deleterious interaction with common pharmaceutical medications in the general population. The side effects of administration must be appropriate for the care of radiation terrorism victims with combined injuries.

The process of drug discovery and drug development is complex, requiring significant empirical experimentation, safety/toxicology studies in multiple species, and clinical trials. Attempting to determine the safety and efficacy of drug that will be used before or especially after a nuclear exposure is particularly challenging from a practical and ethical perspective. Data from outcomes in clinical radiotherapy patients given a candidate protector or mitigator drug may often not be helpful. Clinical settings in which radiotherapy patients receive continuous low dose rate radiation administration for whole body or partial body single fraction irradiation as would be the case in inhalation or ingestion of radio-isotopes from a terrorist event are rare. Some information can be obtained from the de-identified records of clinical radiotherapy patients receiving fractionated irradiation in protocols that are known to induce specific toxicities. This strategy is being applied to identify radiation mitigators that may be currently used in the clinic for other purposes. It has been known for decades 


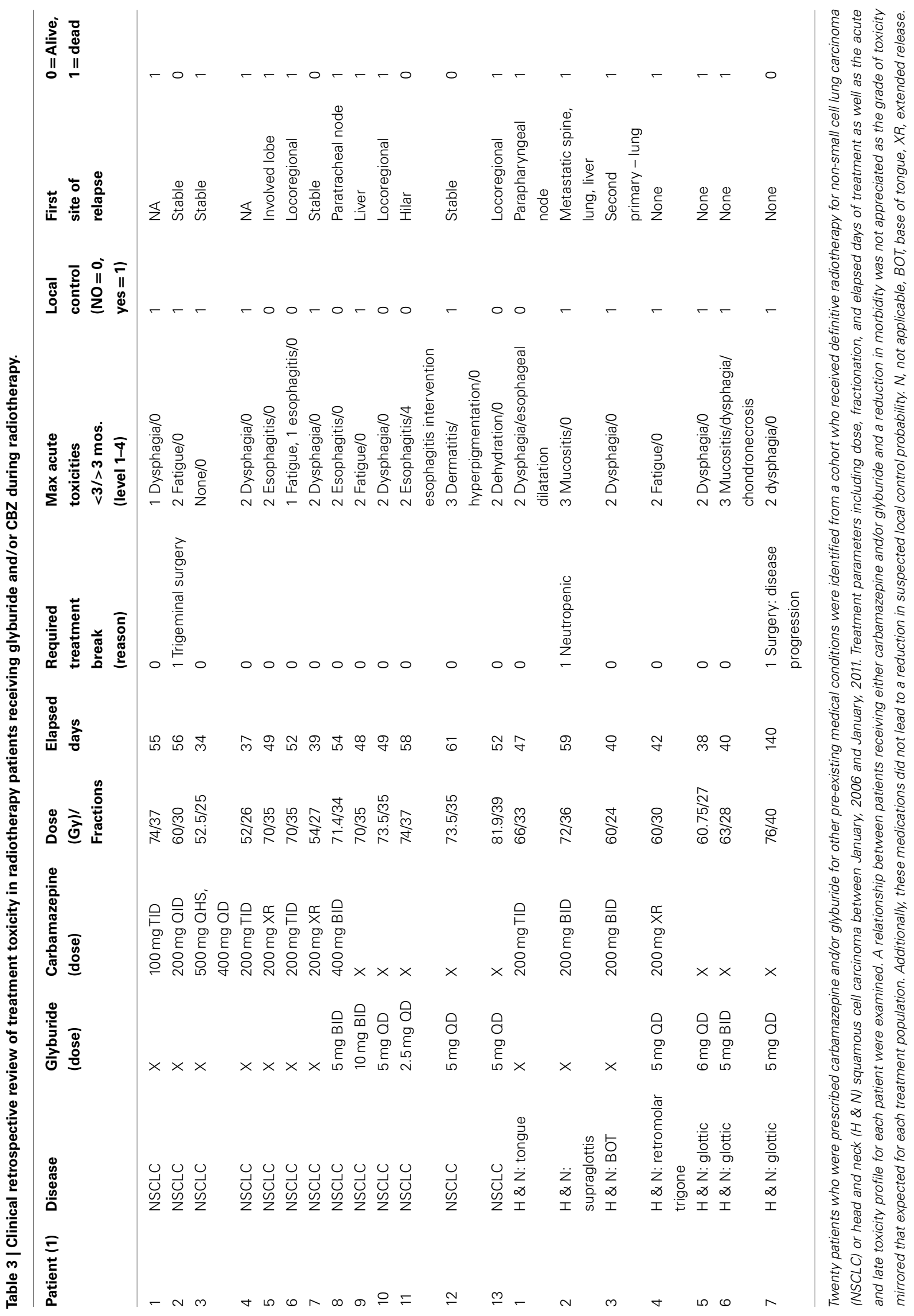


that supportive care regimens including multiple systemic antibiotics and anti-fungal agents help to increase the survival from TBI in both animal models and in clinical bone marrow transplant patients. Only recently, has it been demonstrated that the doxycycline family of antibiotics actually works as radiation mitigators as well as anti-microbials (Epperly et al., 2010c). Would it not be interesting if other commonly available pharmaceutical agents are in fact radiation mitigators? This approach has been taken to analyze the actual radiation mitigating and/or protecting effects of carbamazepine.

Based on the publications relating autophagy to apoptosis, and the potential for counter balancing, effects of these processes in cellular radiation response, we tested the radiation protection and mitigation capacity of carbamazepine, recently shown to be a pro-autophagy drug (Hidvegi et al., 2010; Kim et al., 2011a). Studies in cell culture and in the mouse model demonstrated significant radiation protection and mitigation in this capacity. However, this drug was ineffective as a radiation protector or mitigator for human cells in culture. In retrospective analysis of patient records in clinical radiotherapy in two categories of patients [Gamma Knife Radiosurgery (Flickinger et al., in press) and external beam radiotherapy for head and neck cancer and non-small cell lung cancer], there was no significant decrease in side effects in patients, who were taking carbamazepine at the time and during radiotherapy (Table 3). However, in clinical studies, patients on carbamazepine for long duration prior to radiotherapy, may have adapted alternative pathways to the radiation response and would not have shown radiation protection or mitigation. Furthermore, the high fraction localized radiation delivered in the clinical settings in which retrospective

\section{REFERENCES}

Atkinson, J., Kapralov, A. A., Yanamala, N., Pearce, L., Peterson, J., Tyurina, Y. Y., Epperly, M. W., Huang, Z., Jiang, J., Maeda, A., Feng, W., Wasserloos, K., Belikova, N. A., Tyurin, V. A., Fletcher, J., Wang, Y., Vlasova, I. I., Klein-Seetharaman, J., Stoyanovsky, D. A., Bayir, H., Pitt, B. R., Greenberger, J. S., and Kagan, V. E. (in press). A mitochondriatargeted inhibitor of cytochrome c peroxidase mitigates radiation induced death. Nat. Commun. doi: 10.1038/ncomms1499

Bayir, H., Fadeel, B., Palladino, M. J., Witasp, E., Kurnikov, I. V., Tyurina, Y. Y., Tyurin, V. A., Amoscato, A. A., Jiang, J., Kochamek, P. M., DeKosky, S. T., Greenberger, J. S., Shvedova, A. A., and Kagan, V. E. (2006). Apoptotic interactions of cytochrome c: redox flirting with anionic phospholipids within and outside of mitochondria. Biochim. Biophys. Acta 1757, 648-659.

Belikova, N. A., Jiang, J., Stoyanovsky, D. A., Greenberger, J. S., and Kagan, V. E. (2009a). Mitochondria-targeted (2-hydroxyamino-vinyl)-triphenylphosphonium releases $\mathrm{NO}$ and protects mouse embryonic cells against irradiation-induced apoptosis. FEBS Lett. 583, 1945-1950.

Belikova, N. A., Glumac, A., Rafikov, R., Jiang, J., Greenberger, J. S., Kagan, V. E., and Bayir, H. (2009b). Radioprotection by short-term oxidative preconditioning: role of manganese superoxide dismutase. FEBS Lett. 583, 3437-3442.

Belikova, N. A., Jiang, J., Tyurina, Y. Y., Zhao, Q., Epperly, M. W., Greenberger, J., and Kagan, V. E. (2007). Cardiolipin specific peroxidase reactions of cytochrome $c$ in mitochondria during irradiation induced apoptosis. Int. J. Radiat. Oncol. Biol. Phys. 69, 176-185.

Bernard, M. E., Kim, H., Epperly, M. W., Franicola, D., Zhang, X., Houghton, F., Shields, D., Wang, H., Bakkenist, C. J., Frantz, M. C., Wipf, P., and Greenberger, J. S. (2011a). GSnitroxide (JP4-039) mediated radioprotection of human Fanconi anemia cell lines. Radiat. Res. 176, 603-612.

Bernard, M. E., Kim, H., Rwigema, J. C., Epperly, M. W., Kelley, E. E., Murdoch, G. H., Dixon, T., Wang, H., studies were carried out may not be related to moderate irradiation to $\mathrm{LD}_{30}$ or $\mathrm{LD}_{50 / 30}$ total body doses. If carbamazepine had been shown to be an effective radiation mitigator for human cells and in human retrospective studies of clinical radiotherapy and if a prospective trial would have been considered, the problem of known drug side effects would then have become paramount. Carbamazepine is widely used in the treatment of seizure disorders, manic depressive illness, and trigeminal neuralgia; however, it has side effects (Flickinger et al., in press). In the setting of potential mass casualties in an irradiation counter terrorism event, a concern for a small percentage of patients likely to develop neutropenia leading to bone marrow failure might not be a major problem; however, this complication of carbamazepine is an issue with respect to distribution of the drug to the general population. In the setting of radiation counter measures, the concern for drug side effects might be different from that in the case of multiple administrations for decreasing side effects of clinical radiotherapy.

With the availability of siRNA and chemical library screening techniques (Zellefrow et al., in press), automated chemical synthesis, chemoinformatics, and structural biology, it is clear that new valuable radiation damage mitigators and radiation protectors will be reported with increasing frequency in coming years. These discoveries should add to our understanding of the molecular biology of radiation damage as well as in the relevant applications of improving the quality of life for radiotherapy patients and in radiation countermeasures.

\section{ACKNOWLEDGMENT}

Supported by U19-A1068021 from the NIAID/NIH. and Greenberger, J. S. (2011b). Role of the esophageal vagus neural pathway in ionizing irradiation-induced seizures in nitric oxide synthase1 homologous recombination negative NOS1-/- mice. In vivo 25, 861-870.

Bernard, M. E., Kim, H., Rajagopalan, M. S., Stone, B., Salimi, U., Rwigema, J. C., Epperly, M. W., Shen, H., Goff, J., Franicola, D., Dixon, T., Cao, S., Zhang, X., Reynolds, S. D., Wang, H., Stolz, D. B., and Greenberger, J. S. (in press). Repopulation of the irradiation damaged lung with marrow derived cells. In vivo 26, 9-18.

Carpenter, M., Epperly, M. W., Agarwal, A., Nie, S., Hricisak, L., Niu, Y., and Greenberger, J. S. (2005). Inhalation delivery of manganese superoxide dismutase-plasmid/liposomes (MnSOD-PL) protects the murine lung from irradiation damage. Gene Ther. 12, 685-690.

Epperly, M. W., Bray, J. A., Kraeger, S., Zwacka, R., Engelhardt, J., Travis, E., and Greenberger, J. S. (1998). Prevention of late effects of irradiation lung damage by manganese superoxide dismutase gene therapy. Gene Ther. 5, 196-208.
Epperly, M. W., Bray, J. A., Krager, S., Berry, L. A., Gooding, W., Engelhardt, J. F., Zwacka, R., Travis, E. L., and Greenberger, J. S. (1999a). Intratracheal injection of adenovirus containing the human MnSOD transgene protects athymic nude mice from irradiation-induced organizing alveolitis. Int. J. Radiat. Oncol. Biol. Phys. 43, 169-181.

Epperly, M. W., Travis, E. L., Sikora, C., and Greenberger, J. S. (1999b). Magnesium superoxide dismutase (MnSOD) plasmid/liposome pulmonary radioprotective gene therapy: modulation of irradiationinduced RNA for IL-1, TNF- $\alpha$, and TGF- $\beta$ correlates with delay of organizing alveolitis/fibrosis. Biol. Blood Marrow Transplant. 5, 204-214.

Epperly, M. W., Bray, J. A., Esocobar, P., Bigbee, W. L., Watkins, S., and Greenberger, J. S. (1999c). Overexpression of the human MnSOD transgene in subclones of murine hematopoietic progenitor cell line $32 \mathrm{D} \mathrm{cl} 3$ decreases irradiationinduced apoptosis but does not alter $\mathrm{G} 2 / \mathrm{M}$ or $\mathrm{G} 1 / \mathrm{S}$ phase cell cycle arrest. Radiat. Oncol. Investig. 7, 331-342. 
Epperly, M. W., Franicola, D., Zhang, X., Nie, S., Wang, H., Bahnson, A., Shields, D., Goff, J., and Greenberger, J. S. (2006a). Decreased irradiation pulmonary fibrosis in Smad3/- marrow chimeric mice correlates to reduced bone marrow stromal cell migration in vitro. In vivo 20 , 573-582.

Epperly, M. W., Shields, D., Franicola, D., Zhang, X., Cao, S., Carlos, T., and Greenberger, J. S. (2006b). Bone marrow from CD18-/- (MAC-1-/-) homozygous deletion recombinant negative mice demonstrates increased longevity in long-term bone marrow culture and decreased contribution to irradiation pulmonary damage. In vivo 20 , 431-438.

Epperly, M. W., Gretton, J. E., Defillippi, S. J., Sikora, C. A., Liggitt, D., Koe, G., and Greenberger, J. S. (2001a). Modulation of radiation-induced cytokine elevation associated with esophagitis and esophageal stricture by manganese superoxide dismutase-plasmid/liposome (SOD-PL) gene therapy. Radiat. Res. 155, 2-14.

Epperly, M. W., Travis, E. L., Whitsett, J. A., Epstein, C. J., and Greenberger, J. S. (2001b). Overexpression of manganese superoxide dismutase (MnSOD) in whole lung or alveolar type II (AT-II) cells of MnSOD transgenic mice does not provide intrinsic lung irradiation protection. Radiat. Oncol. Investig. 96, 11-21.

Epperly, M. W., Kagan, V. E., Sikora, C. A., Gretton, J. E., Defilippi, S. J., Bar-Sagi, D., and Greenberger, J. S. (2001c). Manganese superoxide dismutase-plasmid/liposome (MnSOD-PL) administration protects mice from esophagitis associated with fractionated irradiation. Int. J. Cancer 96, 221-233.

Epperly, M. W., Guo, H. L., Jefferson, M., Wong, S., Gretton, J., Bernarding, M., Bar-Sagi, D., and Greenberger, J. S. (2003a). Cell phenotype specific duration of expression of epitope-tagged HA-MnSOD in cells of the murine lung following intratracheal plasmid liposome gene therapy. Gene Ther. 10, 163-171.

Epperly, M. W., Bernarding, M., Gretton, J., Jefferson, M., Nie, S., and Greenberger, J. S. (2003b). Overexpression of the transgene for manganese superoxide dismutase (MnSOD) in 32D cl 3 cells prevents apoptosis induction by TNF- $\alpha$, IL-3 withdrawal and ionizing irradiation. Exp. Hematol. 31, 465-474.

Epperly, M. W., Guo, H. L., Bernarding, M., Gretton, J., Jefferson, M., and
Greenberger, J. S. (2003c). Delayed intratracheal injection of manganese superoxide dismutase (MnSOD)plasmid/liposomes provides suboptimal protection against irradiationinduced pulmonary injury compared to treatment before irradiation. Gene Ther. Mol. Biol. 7, 61-68.

Epperly, M. W., Sikora, C. A., Defilippi, S., Gretton, J. E., and Greenberger, J. S. (2003d). Bone marrow origin of myofibroblasts in irradiation pulmonary fibrosis. Am. J. Respir. Cell Mol. Biol. 29, 213-224.

Epperly, M. W., Gretton, J. E., Bernarding, M., Nie, S., Rasul, B., and Greenberger, J. S. (2003e). Mitochondrial localization of copper/zinc superoxide dismutase $(\mathrm{Cu} / \mathrm{ZnSOD})$ confers radioprotective functions in vitro and in vivo. Radiat. Res. 160, 568-578.

Epperly, M. W., Melendez, A., Zhang, X., Franicola, D., Smith, T., Greenberger, B. A., Komanduri, P., and Greenberger, J. S. (2009). Mitochondrial targeting of a catalase transgene product by plasmid liposomes increases radioresistance in vitro and in vivo. Radiat. Res. 171, 588-595.

Epperly, M. W., Osipov, A. N., Martin, I., Kawai, K., Borisenko, G. G., Jefferson, M., Bernarding, M., Greenberger, J. S., and Kagan, V. E. (2004a). Ascorbate as a "redox-sensor" and protector against irradiation-induced oxidative stress in 32D cl 3 hematopoietic cells and subclones overexpressing human manganese superoxide dismutase. Int. J. Radiat. Oncol. Biol. Phys. 58, 851-861.

Epperly, M. W., Guo, H. L., Shields, D., Zhang, X., Flanders, K., Lambert, P., and Greenberger, J. S. (2004b). Correlation of ionizing irradiationinduced late pulmonary fibrosis with long-term bone marrow culture fibroblast progenitor cell biology in mice homozygous deletion recombinant negative for endothelial cell adhesion molecules. In vivo 18, 1-14.

Epperly, M. W., Goff, J. P., Sikora, C. A., Shields, D. S., and Greenberger, J. S. (2004c). Bone marrow origin of cells with capacity for homing and differentiation to esophageal squamous epithelium. Radiat. Res. 162, 233-240.

Epperly, M. W., Carpenter, M., Agarwal, A., Mitra, P., Nie, S., and Greenberger, J. S. (2004d). Intraoral manganese superoxide dismutase plasmid liposome radioprotective gene therapy decreases ionizing irradiation-induced murine mucosal cell cycling and apoptosis. In vivo 18, 401-410.
Epperly, M. W., Shen, H., Jefferson, M., and Greenberger, J. S. (2004e). In vitro differentiation capacity of esophageal progenitor cells with capacity for homing and repopulation of the ionizing irradiation damaged esophagus. In vivo 18, 675-685.

Epperly, M. W., Sikora, C., Defilippi, S., Bray, J., Koe, G., Liggitt, D., Luketich, J. D., and Greenberger, J. S. (2000a). Plasmid/liposome transfer of the human manganese superoxide dismutase (MnSOD) transgene prevents ionizing irradiationinduced apoptosis in human esophagus organ explants culture. Int. J. Cancer 90, 128-137.

Epperly, M. W., Defilippi, S., Sikora, C., Gretton, J., Kalend, K., and Greenberger, J. S. (2000b). Intratracheal injection of manganese superoxide dismutase (MnSOD) plasmid/liposomes protects normal lung but not orthotopic tumors from irradiation. Gene Ther. 7, 1011-1018.

Epperly, M. W., Epstein, C. J., Travis, E. L., and Greenberger, J. S. (2000c). Decreased pulmonary radiation resistance of manganese superoxide dismutase (MnSOD)-deficient mice is corrected by human manganese superoxide dismutaseplasmid/liposome (SOD2-PL) intratracheal gene therapy. Radiat. Res. 154, 365-374.

Epperly, M. W., Sikora, C. A., Defilippi, S. J., Gretton, J. E., Bar-Sagi, D., Carlos, T., Guo, H. L., and Greenberger, J. S. (2002a). Pulmonary irradiationinduced expression of VCAM-1 and ICAM-1 is decreased by MnSODPL gene therapy. Biol. Blood Marrow Transplant. 8, 175-187.

Epperly, M. W., Sikora, C., Defilippi, S. Gretton, J., Zhan, Q., Kufe, D. W., and Greenberger, J. S. (2002b). MnSOD inhibits irradiation-induced apoptosis by stabilization of the mitochondrial membrane against the effects of SAP kinases p38 and Jnk1 translocation. Radiat. Res. 157, 568-577.

Epperly, M. W., Defilippi, S., Sikora, C., Gretton, J., and Greenberger, J. S. (2002c). Radioprotection of lung and esophagus by overexpression of the human manganese superoxide dismutase transgene. Mil. Med. 167, 071.

Epperly, M. W., Smith, T., Wang, H. ., Schlesselman, J., Franicola, D., and Greenberger, J. S. (2008). Modulation of total body irradiation induced life shortening by systemic intravenous MnSOD-plasmid liposome gene therapy. Radiat. Res. 170, 437-444.
Epperly, M. W., Smith, T., Zhang, X., Greenberger, B., Komanduri, P., Wang, H., and Greenberger, J. S. (2010a). Modulation of in utero total body irradiation induced newborn mouse growth retardation by maternal manganese superoxide dismutase-plasmid liposome (MnSOD-PL) gene therapy. Gene Ther. 18, 579-583.

Epperly, M. W., Lai, S. M., Mason, N., Lopresi, B., Dixon, T., Franicola, D., Niu, Y., Wilson, W. R., Kanai, A. J., and Greenberger, J. S. (2010b). Effectiveness of combined modality radiotherapy of orthotopic human squamous cell carcinomas in $\mathrm{Nu} / \mathrm{Nu}$ mice using cetuximab, tirapazamine, and MnSOD-plasmid liposome gene therapy. In vivo 24, 1-8.

Epperly, M. W., Franicola, D., Shields, D., Rwigema, J. C., Stone, B., Zhang, X., McBride, W., Georges, G., Wipf, P., and Greenberger, J. S. (2010c). Screening for in vitro radiation protection and mitigation capacity of antimicrobial agents including those used in supportive care regimens for bone marrow transplant recipients. In vivo 24, 9-20.

Epperly, M. W., Rwigema, J. C. M., Li, S., Gao, X., Wipf, P., Goff, J., Wang, H., Franicola, D., Shen, H., Kagan, V., Bernard, M., and Greenberger, J. S. (2010d). Intraesophageal administration of GS-nitroxide (JP4-039) protects against ionizing irradiationinduced esophagitis. In vivo 24, 811-821.

Epperly, M., Brand, R., Stottlemyer, J., Dixon, T. M., Gao, X., Li, S., Huq, S., Wipf, P., Falo, L. D., and Greenberger, J. S. (2010e). Topical application of GS-nitroxide JP4-039 emulsion mitigation ionizing irradiation induced skin burns. Int. J. Radiat. Oncol. Biol. Phys. 78(Suppl. 3), S634.

Epperly, M. W., Wang, H., Jones, J., Dixon, T., Montesinos, C. and Greenberger, J. S. (2011). Antioxidant-chemoprevention diet ameliorates late effects of total body irradiation and supplements radioprotection by MnSOD-plasmid liposome administration. Radiat. Res. 175, 759-765.

Epperly, M. W., Wegner, R., Kanai, A. J., Kagan, V., Greenberger, E. E., Nie, S., and Greenberger, J. S. (2007a). Irradiated murine oral cavity orthotopic tumor antioxidant pool destabilization by MnSOD-plasmid liposome gene therapy mediates tumor radiosensitization. Radiat. Res. 267, 289-297.

Epperly, M. W., Cao, S., Zhang, X., Franicola, D., Kanai, A. J., 
Greenberger, E. E., and Greenberger, J. S. (2007b). Increased longevity of hematopoiesis in continuous bone marrow cultures derived from mtNOS-/- homozygous recombinant negative mice correlates with increased radioresistance of hematopoietic and bone marrow stromal cells. Exp. Hematol. 35, 137-145.

Epperly, M. W., Epperly, L. D., Zhang, X., Franicola, D., and Greenberger, J. S. (2007c). Overexpression of MnSOD transgene product protects cryopreserved bone marrow hematopoietic progenitor cells form ionizing irradiation. Radiat. Res. 168, 560-566.

Epperly, M., Jin, S. Q., Nie, S., Cao, S., Zhang, X., Franicola, D., Fink, M., and Greenberger, J. S. (2007d). Ethyl pyruvate, a potentially effective total body irradiation damage mitigator. Radiat. Res. 168, 552-559.

Epperly, M. W., Zhang, X., Nie, S., Cao, S., Kagan, V., Tyurin, V., and Greenberger, J. S. (2005a). MnSOD-plasmid liposome gene therapy effects on ionizing irradiation induced lipid peroxidation of the esophagus. In vivo 19, 997-1004.

Epperly, M. W., Shen, H., Zhang, X., Nie, S., Cao, S., and Greenberger, J. S. (2005b). Protection of esophageal stem cells from ionizing irradiation by MnSOD-plasmid liposome gene therapy. In vivo 19, 965-974.

Fink, M. P., Macias, C. A., Xiao, J., Tyurina, Y. Y., Delude, R. L., Greenberger, J. S., Kagan, V. E., and Wipf, P. (2007a). Hemigramicidin-TEMPO conjugates: novel mitochondriatargeted antioxidants. Biochem. Pharmacol. 74, 801-809.

Fink, M., Macias, C. A., Xiao, J., Tyurina, Y. Y., Delude, R. L., Greenberger, J. S., Kagan, V. E., and Wipf, P. (2007b). Hemigramicidin-TEMPO conjugates: novel mitochondriatargeted antioxidants. Crit. Care Med. 35, 5461-5470.

Flickinger, J. C. Jr., Kim, H., Kano, H., Greenberger, J. S., Lunsford, L. D., Kondziolka, D., and Flickinger, J. C. Sr. (in press). Do carbamazepine, gabapentin, or other anticonvulsants exert sufficient radioprotective effects to alter responses to trigeminal neuralgia radiosurgery? Int. J. Radiat. Oncol. Biol. Phys.

Goff, J. P., Epperly, M. W., Shields, D., Wipf, P., Dixon, T., and Greenberger, J. S. (2011). Radiobiologic effects of GS-nitroxide (JP4-039) in the hematopoietic syndrome. In vivo 25, 315-324.

Gokhale, A. S., Epperly, M., Glowacki, J., Wang, H., Wipf, P., Pierce, J. G.,
Dixon, T., Patrene, K., and Greenberger, J. S. (2010). Small molecule GS-nitroxide and MnSOD gene therapy ameliorate ionizing irradiation-induced delay in bone wound healing in a novel murine model. In vivo 24, 377-386.

Greenberger, J. S. (2008). Gene therapy approaches for stem cell protection. Gene Ther. 15, 100-108.

Greenberger, J. S. (2009). Radioprotection. In vivo 23, 323-336.

Greenberger, J. S., and Epperly, M. W. (2007). Antioxidant therapeutic approaches toward amelioration of the pulmonary pathophysiological damaging effects of ionizing irradiation. Curr. Respir. Med. Rev. 3, 29-37.

Greenberger, J. S., and Epperly, M. W. (2009). Bone marrow-derived stem cells and radiation response. Semin. Radiat. Oncol. 19, 133-139.

Greenberger, J. S., Epperly, M. W., Gretton, J., Jefferson, M., Nie, S., Bernarding, M., Kagan, V., and Guo, H. L. (2003). Radioprotective gene therapy. Curr. Gene Ther. 3, 183-195.

Greenberger, J. S., Kagan, V. E., Pearce, L., Boriseniao, G., Tyurina, Y., and Epperly, M. W. (2001). Modulation of redox signal transduction pathways in the treatment of cancer. Antioxid. Redox Signal. 3, 347-359.

Guo, H. L., Seixas-Silva, J. A., Epperly, M. W., Gretton, J. E., Shin, D. M., and Greenberger, J. S. (2003a). Prevention of irradiation-induced oral cavity mucositis by plasmid/liposome delivery of the human manganese superoxide dismutase (MnSOD) transgene. Radiat. Res. 159, 361-370.

Guo, H. L., Epperly, M. W., Bernarding, M., Nie, S., Gretton, J., Jefferson, M., and Greenberger, J. S. (2003b). Manganese superoxide dismutase-plasmid/liposome (MnSOD-PL) intratracheal gene therapy reduction of irradiationinduced inflammatory cytokines does not protect orthotopic Lewis lung carcinomas. In vivo 117, 13-22. Guo, H. L., Wolfe, D., Epperly, M. W., Huang, S., Liu, K., Glorioso, J. C., Greenberger, J. S., and Blumberg, D. (2003c). Gene transfer of human manganese superoxide dismutase protects small intestinal villi from radiation injury. J. Gastrointest. Surg. 7, 229-236.

Hall, E. J., and Giaccia, A. J. (2006). Radiobiology for the Radiologist, 6th Edn. Philadelphia, PA: Lippincott Williams \& Wilkins.

Hidvegi, T., Ewing, M., Hale, P., Dippold, C., Beckett, C., Kemp, C.,
Maurice, N., Mukherjee, A., Goldbach, C., Watkins, S., Michalopoulos, G., and Perlmutter, D. H. (2010). An autophagy-enhancing drug promotes degradation of mutant $\alpha 1$-antitrypsin $Z$ and reduces hepatic fibrosis. Science 329, 229-235.

Jiang, J., Belikova, N. A., Xiao, J., Zhao, Q., Greenberger, J. S., Wipf, P., and Kagan, V.E. (2008). A mitochondriatargeted nitroxide/hemi-gramicidin $S$ conjugate protects mouse embryonic cells against $\gamma$-irradiation. Int J. Radiat. Oncol. Biol. Phys. 70, 816-825.

Jiang, J., Kurnikov, I., Belikova, N. A., Xiao, J., Zhao, Q., Vlasova, I. L., Amoscato, A. A., Braslau, R., Studer, A., Fink, M. P., Greenberger, J. S., Wipf, P., and Kagan, V. E. (2007). Structural requirements for optimized delivery, inhibition of oxidative stress, and anti-apoptotic activity of targeted nitroxides. J. Pharmacol. Exp. Ther. 320, 1050-1060.

Jiang, J., McDonald, P., Dixon, T. M., Franicola, D., Zhang, X., Nie, S., Epperly, L. D., Kagan, V. E., Lazo, J. S., Epperly, M. W., and Greenberger, J. S. (2009a). Druggable genome siRNA library screening identifies Glybencamide as a novel radioprotector. Radiat. Res. 172, 414-422.

Jiang, J., Stoyanovsky, D., Belikova, N. A., Tyurina, Y. Y., Zhao, Q., Tungekar, M. A., Kapralova, V., Huang, Z., Mintz, A., Greenberger, J. S., and Kagan, V. E. (2009b). A mitochondria-targeted triphenylphosphonium-conjugated nitroxide functions as a radioprotector/mitigator. Radiat. Res. 172, 706-714.

Kagan, V. E., Bayir, A., Bayir, H., Stoyanovsky, D., Borisenko, G. G. Tyurina, Y. Y., Wipf, P., Atkinson, J., Greenberger, J. S., Chapkin, R. S., and Belikova, N. A. (2009a). Mitochondria-targeted disruptors and inhibitors of cytochrome c/cardiolipin peroxidase complexes: a new strategy in anti-apoptotic drug discovery. Mol. Nutr. Food Res. 53, 104-114.

Kagan, V. E., Bayir, H. A., Belikova, N. A. Kapralov, O., Tyurina, Y. Y., Tyurin, V. A., Jiang, J., Stoyanovsky, D. A., Wipf, P., Kochanek, P., Greenberger, J. S., Pitt, B., Shvedova, A. A., and Borisenko, G. (2009b). Cytochrome c/cardiolipin relations in mitochondria: a kiss of death. Free Radic. Biol. Med. 46, 1439-1453.

Kagan, V. E., Wipf, P., Stoyanovsky, D., Greenberger, J. S., Borisenko, G., Belikova, N. A., Yanamala, N., Samhan, A. A. K., Tungekar, M. A.,
Jiang, J., Tyurina, Y. Y., Ji, J., KleinSeetharaman, J., Pitt, B. R., Shvedovah, A. A., and Bayir, H. (2009c). Mitochondrial targeting of electron scavenging antioxidants: regulation of selective oxidation vs. random chain reactions. Adv. Drug Deliv. Rev. 61, 1375-1385.

Kagan, V. E., Tyurina, Y. Y., Bayir, H., Chu, C. T., Kapralov, A. A., Vlasova, I. I., Belikova, N. A., Tyurin, V. A., Amoscato, A., Epperly, M., Greenberger, J., DeKosky, S., Shvedova, A. A., and Jiang, J. (2006). The "pro-apoptotic genies" get out of mitochondria: oxidative lipidomics and redox activity of cytochrome c/cardiolipin complexes. Chem. Biol. Interact. 163, 15-28.

Kanai, A., Epperly, M. W., Pearce, L., Birder, L., Zeidel, M., Meyers, S., Greenberger, J., deGroat, W., Apodaca, G., and Peterson, J. (2004). Differing roles of mitochondrial nitric oxide synthase in cardiomyocytes and urothelial cells. Am. J. Physiol. Heart Circ. Physiol. 286, H13-H21.

Kanai, A. J., Zeidel, M. L., Lavelle, J. P., Greenberger, J. S., Birder, L. A., deGroat, W. C., Apodaca, G. L., Meyers, S. A., Ramage, R., VanBibber, M. M., and Epperly, M. W. (2002). Manganese superoxide dismutase gene therapy protects against irradiationinduced cystitis. Am. J. Physiol. 44, 1152-1160.

Kim, H., Epperly, M. W., Flickinger, J. Jr., Bernard, M., and Greenberger, J. S. (2011a). The pro-autophagy drug carbamazepine is a radiation protector and mitigator. Int. J. Radiat. Biol. 87, 1052-1060.

Kim, H., Bernard, M. E., Epperly, M. W., Shen, H., Amoscato, A., Dixon, T. M., Doemling, A. S., Li, S., Gao, X., Wipf, P., Wang, H., Zhang, X., Kagan, V. E., and Greenberger, J. S. (2011b). Amelioration of radiation esophagitis by orally administered $\mathrm{p} 53 / \mathrm{mdm} 2 / \mathrm{mdm} 4$ inhibitor (BEB55) or GS-nitroxide. In vivo 25, 841-849.

Koide, K., Osman, S., Garner, A. L., Song, F., Dixon, T., Greenberger, J. S., and Epperly, M. W. (2011). The use of 3, 5,4-tri-O-acetylresveratrol as a potential product for resveratrol protects mice from $\gamma$-irradiationinduced death. ACS Med. Chem. Lett. 2, 270-274.

Lechpammer, S., Epperly, M. W., Zhou, Z., Nie, S., Glowacki, J., and Greenberger, J. S. (2005). Antioxidant pool regulated adipocyte differentiation SOD2-/- bone marrow stromal cells. Exp. Hematol. 33, 1201-1208.

Movsas, B., Scott, C., Langer, C., WernerWasik, M., Nicoalou, N., Komaki, 
R., Machtay, M., Smith, C., Axelrod, R., Sarna, L., Wasserman, T., and Byhardt, R. (2005). Randomized trial of amifostine in locally advanced non-small cell lung cancer patients receiving chemotherapy and hyeprfractionated radiation: radiation therapy oncology group trial. J. Clin. Oncol. 23, 2145-2154.

Mustata, G., Li, M., Zevola, N., Bakan, A., Zhang, L., Epperly, M., Greenberger, J. S., Yu, J., and Bahar, I. (2011). Development of small molecule PUMA inhibitors for mitigating radiation-induced cell death. Curr. Top. Med. Chem. 11, 281-290.

Niu, Y., Wang, H., Wiktor-Brown, D., Rugo, R., Shen, H., Huq, M. S., Engelward, B., Epperly, M., and Greenberger, J. S. (2010). Irradiated esophageal cells are protected from radiation-induced recombination by MnSOD gene therapy. Radiat. Res. 173, 453-461.

Niu, Y. Y., Epperly, M. W., Shen, H., Smith, T., Lewis, D., Gollin, S., and Greenberger, J. S. (2008). Intraesophageal MnSOD-plasmid liposome administration enhances engraftment and self-renewal capacity of bone marrow derived progenitors of esophageal squamous epithelium. Gene Ther. 15, 347-356.

Pearce, L. L., Epperly, M. W., Greenberger, J. S., Pitt, B., and Peterson, J. (2001). Identification of respiratory complexes I and III as mitochondrial sites of damage following exposure to ionizing radiation and nitric oxide. Nitric Oxide 5, 128-136.

Qiu, W., Carson-Walter, E. B., Liu, H., Epperly, M. W., Greenberger, J. S., Zambetti, G. P., Zhang, L., and Yu, J. (2008). PUMA regulates intestinal progenitor cell radiosensitivity and gastrointestinal syndrome. Cell Stem Cell 2, 576-583.

Rajagopalan, M. S., Gupta, K., Epperly, M. W., Franicola, D., Zhang, X., Wang, H., Zhao, H., Tyurin, V. A., Kagan, V. E., Wipf, P., Kanai, A., and Greenberger, J. S. (2009). The mitochondria-targeted nitroxide JP4-039 augments potentially lethal irradiation damage repair. In vivo 23, 717-726.

Rajagopalan, M. S., Stone, B., Rwigema, J. C., Salimi, U., Epperly, M. W., Goff, J., Franicola, D., Dixon, T., Cao, S., Zhang, X., Buchholz, B. M., Bauer, A. J., Choi, S., Bakkenist, C., Wang, H., and Greenberger, J. S. (2010). Intraesophageal manganese superoxide dismutase-plasmid liposomes ameliorates novel total body and thoracic irradiation sensitivity of homologous deletion recombinant negative nitric oxide synthase1 (NOS1-/-) mice. Radiat. Res. 174, 297-312.

Rwigema, J. C. M., Beck, B., Wang, W., Doemling, A., Epperly, M. W., Shields, D., Franicola, D., Dixon, T., Frantz, M. C., Wipf, P., Tyurina, Y., Kagan, V. E., Wang, H., and Greenberger, J. S. (2011). Two strategies for the development of mitochondrial-targeted small molecule radiation damage mitigators. Int. J. Radiat. Oncol. Biol. Phys. 80, 860-868.

Stickle, R. L., Epperly, M. W., Klein, E., Bray, J. A., and Greenberger, J. S. (1999). Prevention of irradiation-induced esophagitis by plasmid/liposome delivery of the human manganese superoxide dismutase (MnSOD) transgene. Radiat. Oncol. Investig. 7, 204-217.

Stone, H. B., Coleman, C. N., Moulder, J. E., Ang, K. K., Anscher, M. S., Barcellos-Hoff, M. H., Dynan, W. S., Fike, J. R., Grdina, D. J., Greenberger, J. S., Hauer-Jensen, M., Hill, R. P., Kolesnick, R. N., MacVittie, T. J., Marks, C., McBride, W. H., Metting, N., Pellmar, T., Purucker, M., Robbins, M. E. C., Schiestl, R. H., Seed, T. M., Tomaszewski, J., Travis, E. L., Wallner, P. E., Wolpert, M., and Zaharevitz, D. (2004). Models for evaluating agents intended for the prophylaxis, mitigation, and treatment of radiation injuries. Report of an NCI Workshop, December 3-4, 2003. Radiat. Res. 162, 711-718.

Stoyanovsky, D. A., Huang, Z., Jiang, J., Belikova, N. A., Tyurin, V., Epperly, M. W., Greenberger, J. S., Bayir, H., and Kagan, V. E. (2011). A manganese-porphyrin complex decomposes hydrogen peroxide, compartmentalizes into mitochondria, inhibits apoptosis, and acts as a radiation mitigator in vivo. ACS Med. Chem. Lett. 362, 21-34.

Stoyanovsky, D. A., Vlasova, I. I., Belikova, N. A., Kapralov, A., Tyurin, V., Greenberger, J. S., and Kagan, V. E. (2009). Targeting and activation of NO donors in mitochondria. Peroxidase metabolism of (2-hydroxyamino-vinyl)-triphenylphosphonium by cytochrome $c$ releases NO and protects cells form apoptosis. FEBS Lett. 583, 2000-2005.

Tarhini, A. A., Belani, C., Luketich, J. D., Ramalingam, S. S., Argiris, A., Gooding, W., Petro, D., Kane, K., Liggitt, D., Championsmith, T.,
Zhang, X., Epperly, M. W., and Greenberger, J. S. (2011). A phase I study of concurrent chemotherapy (paclitaxel and carboplatin) and thoracic radiotherapy with swallowed manganese superoxide dismutase (MnSOD) plasmid liposome (PL) protection in patients with locally advanced stage III non-small cell lung cancer. Hum. Gene Ther. 22 336-343.

Tyurin, V. A., Tyurina, Y. Y., Jung, M. Y., Tungekar, M. A., Wasserloos, K. J., Bayir, H., Greenberger, J. S., Kochanek, P. M., Shvedova, A. A., Pitt, B., and Kagan, V. E. (2009). Mass-spectrometric analysis of hydroperoxy- and hydroxyderivatives of cardiolipin and phosphatidylserine in cells and tissues induced by proapoptotic and pro-inflammatory stimuli. J. Chromatogr. B 877, 2863-2879.

Tyurin, V. A., Tyurina, Y. Y., Kochanek, P. M., Hamilton, R., DeKosky, S. T., Greenberger, J. S., Bayir, H., and Kagan, V. E. (2008). Oxidative lipidomics of programmed cell death. Methods Enzymol. 442, 375-393.

Tyurin, V. A., Tyurina, Y. Y., Ritov, V. B., Lysytsya, A., Amoscato, A. A., Kochanek, P. M., Hamilton, R., DeKosky, S. T., Greenberger, J. S., Bayir, H., and Kagan, V. E. (2010). Oxidative lipidomics of apoptosis: quantitative assessment of phospholipid hydroperoxides in cells and tissues. Mol. Biol. 610, 353-374.

Tyurina, Y. Y., Tyurin, V. A., Epperly, M. W., Greenberger, J. S., and Kagan, V. E. (2008). Oxidative lipidomics of $\gamma$-irradiation induced intestinal injury. Free Radic. Biol. Med. 44, 299-314.

Tyurin, Y. Y., Tyurin, V. A., Kapralova, V. I., Wasserloos, K., Mosher, M., Epperly, M., Greenberger, J., Pitt, B. R., and Kagan, V. E. (2011). Oxidative lipidomics of $\gamma$-irradiation induced lung injury: mass-spectrometric characterization of cardiolipin and phosphatidylserine peroxidation. Radiat. Res. 175, 610-621.

Wipf, P., Xiao, J., Jiang, J., Belikova, N. A., Tyurin, V. A., Fink, M. P., and Kagan, V. E. (2005). Mitochondrial targeting of selective electron scavengers: synthesis and biological analysis of hemigramicidin-tempo conjugates. J. Am. Chem. Soc. 127, 12460-12461.

Zellefrow, C., Sharlow, E. R., Reese, C., Shu, T., Kagan, V., Epperly, M., Greenberger, J., and Lazo, J. S. (in press). Development and deployment of an siRNA assay to identify druggable targets for radiation mitigation. Radiat. Res.

Zhang, Q. S., Eaton, L., Snyder, E. R., Houghtaling, S., Mitchell, J. B., Finegold, M., Van Waes, C., and Grompe, M. (2008a). Tempol protects against oxidative damage and delays epithelial tumor onset in Fanconi anemia mice. Cancer Res. 68, 1601-1608.

Zhang, X., Epperly, M. W., Kay, M. A., Chen, Z. Y., Smith, T., Franicola, D., Greenberger, B. A., Komanduri, P., and Greenberger, J. S. (2008b). Radioprotection in vitro and in vivo by minicircle plasmid carrying the human manganese superoxide dismutase transgene. Hum. Gene Ther. 19, 820-826.

Zhou, S., Greenberger, J. S., Epperly, M. W., Goff, J. P., Adler, C., LeBoff, M. S., and Glowacki, J. (2008). Agerelated intrinsic changes in human bone marrow-derived mesenchymal stem cells and their differentiation to osteoblasts. Aging Cell 7, 335-343.

Zwacka, R. M., Dudus, L., Epperly, M. W., Greenberger, J. S., and Engelhardt, J. F. (1998). Redox gene therapy protects human IB-3 lung epithelial cells against ionizing radiation-induced apoptosis. Hum. Gene Ther. 9, 1381-1386.

Conflict of Interest Statement: The authors declare that the research was conducted in the absence of any commercial or financial relationships that could be construed as a potential conflict of interest.

Received: 01 December 2011; paper pending published: 19 December 2011; accepted: 20 December 2011; published online: 13 January 2012.

Citation: Greenberger JS, Clump D, Kagan V, Bayir H, Lazo JS, Wipf P, Li S, Gao X and Epperly MW (2012) Strategies for discovery of small $\mathrm{mol}$ ecule radiation protectors and radiation mitigators. Front. Oncol. 1:59. doi: 10.3389/fonc.2011.00059

This article was submitted to Frontiers in Radiation Oncology, a specialty of Frontiers in Oncology. Copyright (c) 2012 Greenberger, Clump, Kagan, Bayir, Lazo, Wipf, Li, Gao and Epperly. This is an open-access article distributed under the terms of the Creative Commons Attribution Non Commercial License, which permits noncommercial use, distribution, and reproduction in other forums, provided the original authors and source are credited. 